\title{
The Impact of Reading Strategy Training on the Reading Comprehension of Iranian EFL Learners
}

\author{
Hamid Reza Khalaji \\ Dpt. of English, Islamic Azad University, Malayer Branch, Iran \\ Email: hrkhalaji@yahoo.com \\ Karim Vafaeeseresht \\ Dpt. of English, Islamic Azad University, Malayer Branch, Iran \\ Email: km_vafa@yahoo.com
}

\begin{abstract}
This article examines the strategies training teachers employ in various stages of instruction in classroom language learning. Therefore, this study aims at determining the difference in the strategy use by readers at an upper-intermediate level. The subjects of this study were preparatory ELT students at Islamic Azad University, Malayer branch. The students were administered an inventory of strategy use during their in-classroom reading studies. Data was analyzed through a percentage study. It was reported in the study that readers participating in strategy training courses differed significantly from those who did not. By recognizing the differences between the two groups during the reading stage, foreign language teachers were advised to manipulate training their students in reading strategies before starting the reading courses. A sentence or a paragraph may also help the reader to understand a specific word (the contextual meaning). The students should be guided to make use of the strategies they have already learned to reach and capture the meaning (the message) given in the reading material.
\end{abstract}

Index Terms — reading comprehension, strategy, training, reading materials

\section{INTRODUCTION}

Nowadays English is regarded as an international language. Because of this status it has been widely used in different areas such as commerce, education as well as the internet. With these uses of English, there are created so many needs to this language. Reading is undoubtedly one of the important factors which should be regarded seriously while learning this international language. Because of the importance of this skill, there are naturally many ways to improve the ways the students read and comprehend a passage. Many researchers have focused on these ways and have carried out some studies in various parts of the world to explore the best ways from which a reader can benefit from his or her reading skills. They have changed the classroom activities hoping to revolute the reading comprehension. Thus new and modern methods have been proposed some of which have been proved to be fruitful, while others have not been so useful.

But after some time, researchers understood that these techniques and methods did not help learning by themselves. There was another dimension to language learning: individual differences such as age, interest, gender, and so on. Grenfell and Harris (1999) pointed at this important fact by saying "Methodology alone can never be a solution to language learning. Rather it is an aid and suggestion" (p. 10).

In this era the researchers have reached to a very important conclusion. The conclusion has been that instead of focusing on the reading methods and wasting the time with the methodology of language teaching it is better to invest some time on individual differences and find out the ways in which each learner can benefit more from his or her reading. This shift led to an increase in the number of studies carried out regarding learner characteristics and second language learning. One of the most popular aspects of study was language learning strategies.

\section{LITERATURE REVIEW}

A lot of theorizers have drawn their attention towards reading comprehension and strategy training because of the importance of the issues. Followings we have mentioned the most relevant literature to provide the reader with the necessary background.

\section{A. The Definition of Reading}

Learning in general is a very demanding process. Concerning language learning the matter becomes much more complicated. It not only involves learning the structures, vocabulary items, some idiomatic expressions and cultural aspects of the language but it also involves being proficient in the skills needed to understand and communicate in the target language effectively. There are many skills required in a language but the main ones are listening, reading, writing and speaking. The first two are the receptive skills while the latter two are the productive ones. Without a full mastery of the receptive skills, it is difficult to achieve mastery in productive ones. 
Reading is one of the receptive skills which is of great importance in language teaching and learning. There are many reasons for its being important. Firstly, learners come across it a lot in their daily lives. Secondly, since the students in this research are preparatory learners who are learning English for academic purposes, it is definite that they will have to read a lot of long articles or books in their departments. Without understanding the texts, they cannot learn anything; as a result, cannot be successful in the exams.

Since reading is an important skill in language learning, it is necessary to define it. Aebersold and Field (1997) define reading as follows: "Reading is what happens when people look at a text and assign meaning to the written symbols in that text" (p. 15). In this definition, there are two necessary entities for the process: the text and the reader. Reading as a skill is then the interaction between these two entities. According to Stauffer (1969) reading means "getting information from the printed page" (p. 5). It can be concluded from this definition that one of the reasons for reading is to get some information out of the text in order to find out something or in order to do something with the information you get. It may not be necessary to read a text fully depending on the purpose. Therefore, readers develop some strategies to deal with reading. As Wallace (1992) says "Experienced readers make judgments during any reading activity about the degree of care and attention which the material warrants. In the real world, effective reading means a flexible and appropriate response to the material in hand, and this is always guided by the reader's options, including the option to give up" (p. 5). While one is reading a text, there is always a purpose in his/her mind because reading is a purposeful activity. In this sense, the purpose for reading determines how the text should be read. If the person is looking for a number in a telephone directory, s/he should be very selective. S/he should scan the directory for the number needed. On the contrary, a researcher needs to read an article in detail to get the main ideas of the writer and to learn more about the subject. Nevertheless, it can still be argued that any reading is selective. Wallace (1992) shares the same idea by saying, "Just as we filter spoken messages in deciding what to attend to, so do we filter written messages. And even when we commit ourselves to a full reading, that reading will still be selective, some parts being read with greater care than others" (p. 5).

\section{B. The Importance of Reading Strategies}

Reading is one of the most important skills which a person has to deal with throughout his life time. It needs a lot of practice and experience to understand a passage and the information conveyed in it. The matter becomes more complicated when the text appears in a foreign language in which the reader is not proficient enough. However, there are always some clues which guide the reader. As Wallace (1992) said "There are two things which we all know about language: first that we use it for a purpose; second that it only makes sense in context, that is as part of a larger text or in a situation" (p. 3). It is not always easy to understand a passage carefully without using certain strategies. Strategies are defined as "specific methods of approaching a problem or task, modes of operation for achieving a particular end, planned designs for controlling and manipulating certain information" by Brown (1994, p. 104). As it can be understood from the definition, strategies are not easy to explore and use especially in a foreign language. This is where the language teacher comes onto the stage. The duty of a teacher is then to guide and teach learners how to be effective readers in a foreign language.

\section{The Important Points in Teaching Reading Comprehension}

It can be said that reading is a complicated skill. As Richards (quoted in Aebersold and Field, 1997) says, Reading in a second language is a dynamic and interactive process in which learners make use of background knowledge, text schema, lexical and grammatical awareness, L1- related knowledge, and real world knowledge, as well as their own personal purposes and goals, to arrive at an understanding of written material. At the same time readers' teachers' views of the nature of reading are seen to be shaped by their own social, cultural, and personal histories (p. ix).

When reading a text, both the writer and the reader are actively engaged in the process. While the writer is trying to convey the message implicitly or explicitly stated in the passage, the reader is busy with decoding that message. However, it is not as easy as it may seem. There are lots of things to consider while teaching reading in a foreign language.

In recent years, there have been great developments in the field of English language teaching. One of the earliest considerations was a new approach to reading. In this approach, two different processes were introduced to language teaching and learning. These were namely bottom-up and top-down processing.

\section{Bottom-up Processing}

"In bottom-up processing, readers must first recognize a multiplicity of linguistic signals (letters, morphemes, syllables, words, phrases, grammatical cues, discourse markers) and use their linguistic data-processing mechanisms to impose some sort of order on these signals" (Brown, 2001, p. 299). In order to do this, one should have a good knowledge of the language itself so that the signals which make sense can be selected easily. Nuttall (1996) likens bottom-up processing to "... a scientist with a magnifying glass or microscope examining all the minute details of some phenomenon" (p. 16). Therefore, as a teacher, one can move from grammar points and vocabulary to direct the learners to focus on the message. However, there is one disadvantage of bottom-up processing. Language learners are sometimes too much interested in individual words or phrases that they forget about the overall meaning of the text so teachers 
must be aware of this problem and must be ready to take any immediate actions where necessary in order not to lose the wood for the trees.

\section{E. Top-down Processing}

In top-down processing, learners draw on their intelligence and experience to understand a text (Brown, 2001). Readers come to the reading process with some knowledge of the world around them in their mind and they use this knowledge to make sense of a text. According to Nuttall (1996), a reader using top-down processing is like an eagle overlooking the landscape below. Top-down processing is useful to get the overall meaning of a text.

In language classes, students are required to have general predictions about the text and then seek for the writer's message. Therefore, a teacher can give some ideas to form generalizations about the topic to process the information as an initiator. Then the students are required to process information in the text (Saricoban, 2002).

In the past, lots of reading specialists defended bottom-up processing as being the best way to teach reading. However, more recent research has shown that a reading lesson should make use of both bottom-up and top-down processing, called as "interactive reading". Since both of the processes are equally important in reading, a combination of them would be the best solution. In both modes of processing, students will need different strategies to improve their reading skills.

\section{F. Schema Theory}

What has been referred as the students' background knowledge about the world around them in top-down processing is called as their schemata. A text does not carry meaning on its own. The reader brings his experiences, emotions and cultural knowledge, that is, schemata, to the text and refers back to these to make sense of the previously acquired knowledge. According to schema theory, comprehending a text is an interactive process between the readers 'background knowledge and the text itself (Saricoban, 2002).

There are three different kinds of schemata that are used in the reading process. One of them is the content schema. "It provides readers with a foundation, a basis for comparison" (Aebersold and Field, 1997, p. 16). Using their content schema, readers can compare an event in the text with an event they have experienced before or with similar events in their culture such as a wedding. The other one is formal schema, "which refers directly to the organizational forms and rhetorical structures of written texts" (Aebersold and Field, 1997, p. 17). Before they start actual reading, readers know that a newspaper article is different from a personal note or a letter. The knowledge readers bring to a text about structure, vocabulary, grammar, and level of formality constitutes formal schema. The last schema type is linguistic schema, which includes the decoding features readers need to recognize words and see how they fit together in a sentence.

\section{G. Learning Strategies}

It is hard to deal with a new language and try to understand something written in it. The possible solution for this is to adopt some strategies to cope with the text. There have been many researchers interested in learning strategies and they define the term 'learning strategies' differently. According to Ellis (1994), "A learning strategy is 'an attempt to develop linguistic and sociolinguistic competence in the target language"” (p. 530). Another researcher Oxford (quoted in Ellis, 1994) defines it as "... behaviors or actions which learners use to make language learning more successful, selfdirected and enjoyable" (p. 531). By looking at the last definition, it can be said that Oxford sees learning strategies as behavioral. Another researcher Rubin (quoted in Hedge, 2000) defines learner strategies as "any set of operations, steps, plans, routines used by the learner to facilitate the obtaining, storage, retrieval and use of information, ... that is, what learners do to learn and do to regulate their learning" (p. 77). In the definition, there are two concepts: what learners do to learn and what learners do to regulate their learning. The former involves strategies that deal directly with the second language (cognitive strategies) and the latter involves strategies that manage learning (metacognitive strategies). As a language teacher, one should know whether it is possible to help learners acquire and develop strategies of either kind which will enhance their ability to learn inside or outside the classroom. (Hedge, 2000)

Any language teacher one should be aware of his/her students' needs and weaknesses and start working on them directly. The teacher should design the lessons in such a way that the students will be guided to become efficient readers. As Wallace (1992) points out "Good learners tend to use the same strategies as good experienced readers, drawing on as much of the surrounding text as possible, being prepared to tolerate uncertainty, using a wide range of textual cues in predicting what comes next, and generally being flexible in their response to the texts. The teacher, by watching the various ways in which his or her learners process texts, can encourage the use of those strategies which are observed to be most effective" (p. 59).

Some of the reading strategies and skills are:

1. predicting

2. skimming

3. scanning

4. detailed reading

5. guessing unknown words

6. understanding main ideas 
7. inferring

8. understanding text organization

9. assessing a writer's purpose

10. evaluating a writer's attitude

\section{Methodology}

\section{A. Participants}

Two upper-intermediate level groups participated in the study. All of the students in the groups, aged between 18-20 were selected from among the upper intermediate EFL students of IAU, Malayer Branch. They took part in the coeducational classes, too.

\section{B. Instruments}

The materials used in the present study were reading passages selected from among the passages of Developing Reading Skills. The passages were interesting enough to raise the students' motivation. The mentioned passages were accompanied with pictures so that the students in the experimental group could talk and collaborate on their meaning in a better way.

The data for the study were collected via quantitative and qualitative data collection instruments. The pretest and the posttest results provided the quantitative data, and the qualitative data came from the students' interviews which were carried out after each strategy training session.

\section{The Pretest and the Posttest}

At the beginning of the study, before the training sessions, both of the groups were given a pretest in reading. After the test, the students carried out their lessons as mentioned above for 16 weeks. At the end of 16 weeks, the students received a posttest to see whether the experimental group differed significantly from the control group in the development of reading strategies. The posttest was prepared in accordance with the pretest. In terms of topic selection, it was aimed not to bias the students with a different topic so the same topic with a different point of view was chosen. The questions were prepared considering the training sessions and the objectives of the course. Before students took the test, the same procedure was followed. It was again proofread by the same expert instructors.

\section{Interviews with Students}

An interview was conducted with each of the students in the experimental group in Farsi at the end of the study. It consisted of 6 questions aiming at getting an overall feedback from the students with regard to two components of this study, which were the reading strategies covered in each session and the students' written feedback to these sessions.

In fact, not all the students were inclined to have the interview. There were about 3 or 4 students who came to the interviews just because the researchers called them on an appointment basis. These were the students who were also not so interested in the strategy training sessions. These students were mainly the ones who were expected to fail the course because they did not like English at all. They had the same tendency in all the lessons not only in strategy training ones. Apart from these students, the others were all eager to take part in the interviews.

\section{E. Design and Procedure}

In the first group, namely the control group, there were 20 students. These students received no specific training on reading strategies. They followed their course books and did the reading exercises as they appeared in the book. In the second group, the experimental group, there were also 20 students. These students were specifically trained in reading strategies to improve their reading skills. The experimental group also followed the course book but the reading texts and exercises in the book were exploited in different ways to serve the purpose of strategy training.

The experimental group was taught by one of the researchers who was the teacher of the group; however, the control group had another teacher. The researchers informed the other teacher about the study and the importance of following the course book only in the control group's class. In the end, they came up with the following solution: The control group's reading lessons were to be carried out by the one of the researchers only and the objectives related to other skills such as grammar, writing and revision to be covered by the main class teacher.

The teacher of the control group did not teach any reading lesson in his class. In addition to actual reading lessons, the students also dealt with reading in their writing and grammar lessons, but in these lessons, teaching reading or strategy training was not the main aim. Therefore, they are excluded from this study as reading lessons.

At the beginning of the study, a pretest covering the objectives that the students were expected to achieve in reading such as understanding main ideas and text cohesion, guessing meaning from the context was administered to both groups. The test was administered to another upper intermediate class to get the reliability of the test and it was found to be 0.91 . After the pretest, the students in the experimental group received strategy training for 16 weeks while the students in the control group continued to follow the course books only.

During the training sessions, the students were informed from the strategies used in reading and were encouraged to use them in their further reading as well. They also took part in an interview after each session in which they were asked 
to answer the questions that the researchers provided them with. Then, at the end of the 16-week training, both groups took a posttest, again designed by the researchers, to see if there was a difference in the students' performances after the training they had received.

\section{F. The Purpose of the Study}

The purpose of this study was to determine whether an approach to teaching reading through using the strategy training into the instruction would yield a better reading performance than teaching reading following the course book alone at upper intermediate level. It was an exploratory experimental study. The data were collected through quantitative and qualitative data collection instruments. The pretest and the posttest results provided the quantitative data, and the qualitative data came from the interviewing with individual students carried out after each strategy training session according to the questions that the researchers had provided to see if the students make use of these strategies in their extensive readings out of class and if they would benefit from those strategies.

\section{RESUlts}

Generally the results obtained from this study correspond with what the other researchers have found out. The studies evaluating the effectiveness of strategy training were also carried out for different skills in language learning. Bialystok, O'Malley, Cohen and Aphek (quoted in Ellis, 1994) conducted studies on vocabulary learning strategies. The common conclusion in all of these studies was that students benefited from strategy training in the related field. Another study by O'Malley et al (quoted in Ellis, 1994) investigated the effects of strategy training on the learners' performance on a listening and speaking task. In the end, it was found that while there was not a significant difference in the listening task between the two groups, in the speaking task, the experimental group which was specifically trained on how to present a two-minute talk outperformed the control group.

\section{DisCUSSION AND CONCLUSION}

The researchers were able to make the following generalizations by examining the results of this study:

1. The students of IAU, Malayer branch are mostly unaware of the strategies involved in reading; therefore, they are usually unsuccessful in the exams. Some good readers are, on the contrary, use the strategies they use in their mother tongue.

2. Raising students' awareness on the strategies used in reading works well in reading classes. Students benefit a lot from the activities and turn out to be better readers as the time goes by.

3. Having achieved something which they had found to be very difficult motivates students greatly and encourages them to practice outside the class as well.

4. Written and oral feedback provides a means through which a teacher can gather information on whether activities carried out in lessons work or not. In this way, teachers can find a way to modify their lessons according to students' feelings and needs.

The results of the qualitative data revealed that the students benefited a lot from the activities and made use of the strategies in their further readings. However, they also emphasized some points to consider when these activities are planned to be carried out. They are as follows:

1. One of the most important findings of this study was that the students benefited a lot from the study and realizing the effectiveness of such training, they complained a lot about not receiving this kind of detailed training before. Therefore, both in their journals and in the interviews as well, they emphasized strongly that they would have liked to be trained on reading strategies starting at the very early levels of their language education. In short, it can be concluded from students' responses that such kind of an instruction should start from the first lesson because later on, it becomes difficult for students to change their habits. In addition, they should be done at all levels, not only in the upperintermediate or another specific level.

2. The texts and question types must be similar to the ones that appear in the exams because undoubtedly the main aim of students is to be successful in their exams first.

3. In order to create a suitable environment for a reading lesson, outside factors such as the noise coming from the other classes should be minimized. In other institutions where reading plays a great role in the curriculum, there must be separate reading classes isolated in a silent part of the building. If it is not possible to have separate classes, the institution must make sure that the walls surrounding the classroom are thick enough not to allow for any noise to be heard from the classes next door since students' concentration is quite important in a reading lesson.

To conclude, having taken the limitations of the study into consideration as well, it can be said that the students in the experimental group benefited from the training. They enjoyed the study as well since they were given a chance to see that reading is not difficult if the reader is provided with the necessary strategies and knows when and how to use them. Therefore, both the students and the researchers found the study useful.

\section{IMPLICATIONS AND RECOMMENDATIONS}


Some recommendations can be made if a similar study is to be carried out. First of all, creating strategy awareness requires a lot of time. However, in a limited amount of time, to get the results which have been hypothesized at the beginning of the study is a difficult target to achieve. Therefore, the researchers must be very sure of the instruments to be used in the study. In addition, preparing for the training sessions is both demanding and requires a lot of time so it would be best to pilot the materials prepared beforehand to see if they work or not since it would be very difficult to make the necessary changes as the study goes on.

Secondly, the students also contribute a lot to the study with their feedback journals and the interviews held with them; therefore, they must be made sure that their effort is considered. Either orally or by giving small gifts, they must be appreciated.

In conclusion, bearing everything that is mentioned in mind, it can be said that teachers at Islamic Azad University of Malayer should realize the importance of strategy training and incorporate it in their lessons. In addition, the components of this study can be integrated into the university syllabus or the syllabus of other institutions where reading is considered to be an important skill and objective.

\section{ACKNOWLEDGEMENT}

We would like to express our gratitude to Islamic Azad University, Malayer Branch, IRAN for their financial support in the process of writing this paper which is taken from our research project entitled "Developing Reading Skills in English through Strategy Training at Upper Intermediate in Islamic Azad University, Malayer Branch”. Our sincere thanks go to the participants of this study, the students and teachers. We are also very grateful to the editors of "Journal of Language Teaching and Research" without their help this publication was impossible.

\section{REFERENCES}

[1] Aebersold, J. A. \& Field, M. L. (1997). From Reader to Reading Teacher. Cambridge: Cambridge University Press.

[2] Brown, H. D. (1994). Principles of Language Learning and Teaching. New Jersey: Prentice Hall, Inc.

[3] Brown, H. D. (2001). Teaching by Principles: An Integrative Approach to Language Pedagogy. White Plains, NY: Pearson Education.

[4] Ellis, Rod (1994). The Study of second language acquisition. Oxford: Oxford University Press.

[5] Grenfell, M. \& Harris, V. (1999). Modern Languages and Learning Strategies in Theory and Practice. London: Routledge.

[6] Hedge, T. (2000). Teaching and Learning in the Language Classroom. Oxford: Oxford University Press.

[7] Nuttall, C. (1996). Teaching Reading Skills in a Foreign Language. Oxford: Heinemann.

[8] Saricoban, A. (September 2002). Strategies of successful readers through the three-phase approach. The Reading Matrix, 2(3), $1-16$.

[9] Stauffer, R. G. (1969). Teaching Reading as a Thinking Process. New York: Harper \& Row Publishers, Inc.

[10] Wallace, Catherine. (1992). Language Teaching: A Scheme for Teacher Education Reading. Oxford University Press.

Hamid Reza Khalaji was born in Malayer, Islamic Republic of Iran, in 1971. He is currently a PhD candidate studying Teaching English as a Foreign Language and a faculty member of English Language Department, Islamic Azad University, Malayer Branch, Iran.

He has been teaching English for 13 years at different universities like Islamic Azad Universities of Malayer, Tuyserkan, Hamedan, Arak, and also at Payam-e-Noor university of Malayer.He participated in an International conference in Poland in 2007 and presented a lecture on "The Generation Effect Phenomenon and Learning English Grammar". He has published a book entitled General English for University Students,(Malayer, Hamedan province, Kereshmeh publications, 2006).

Karim Vafaeeseresht got his M.A. in teaching English as a foreign language (TEFL) from Yazd University in 2004.

He has been the Dean of English Department of Islamic Azad University, Malayer Branch, Malyer, Iran from 2009 to 2011 . He is currently the Research Manager of Islamic Azad University, Malayer Branch. 